\title{
Pengaruh Model Pembelajaran PQ4R (Preview, Question, Read, Reflect, Recite Dan Review) With Pop Up Pada Kurikulum 2013 Mata Pelajaran Tematik Kelas V SD Kecamatan Banyudono
}

\author{
Ninda Beny Asfuri ${ }^{1}$, Luncana Faridhoh Sasmito ${ }^{2}$ \\ nindaarjuna@gmail.com ${ }^{1}$ \\ luncanafs@gmail.com² \\ PGSD, FKIP, Universitas Tunas Pembangunan Surakarta
}

\begin{abstract}
Abstrak: Penelitian ini bertujuan untuk mengetahui apakah ada pengaruh Model pembelajaran PQ4R with Pop Up terhadap kreatifitas belajar siswa pada kurikulum 2013 mata pelajaran tematik kelas V dan seberapa besar pengaruhnya. Dari tujuan tersebut maka penelitian ini menggunakan metode quasi eksperimen dengan menggunakan Pretest-Posttest Control-Group Design. Dalam pelaksanaan penelitian subyek penelitian dibagi menjadi dua kelompok yaitu kelompok kontrol dan kelompok eksperimen. Kelompok kontrol diberikan model pembelajaran konvensional sedangkan kelompok eksperimen diberikan model PQ4R with рор ир, kemudian diambil data kreatifitas belajar mata pelajaran tematik dari kedua kelompok. Data kreatifitas belajar mata pelajaran tematik pada kedua kelompok dianalisis menggunakan SPSS untuk menjawab rumusan masalah. Dari analisis data diperoleh 0,000 atau < 0,05 yang berarti bahwa: Ho di tolak dan menerima $\mathrm{H}_{1}$ atau dengan kata lain ada pengaruh yang signifikan antara penggunaan model pembelajaran PQ4R with pop up terhadap kreatifitas belajar mata pelajaran tematik siswa kelas V. Dari uji regresi dengan SPSS didapatkan nilai $\mathrm{R}$ sebesar 0,786 yang berarti bahwa ada pengaruh yang kuat antara model pembelajaran PQ4R with pop up dengan kreatifitas belajar mata pelajaran tematik kurikulum 2013 dan dari nilai $\mathrm{R}$ square didapat nilai 0,625 yang berarti bahwa model pembelajaran $\mathrm{PQ} 4 \mathrm{R}$ with pop up berpengaruh positif terhadap kreatifitas belajar mata pelajaran tematik sebesar $62,5 \%$
\end{abstract}

Kata kunci: Model PQ4R, Pop up, Kreatifitas

\section{THE EFFECT OF THE PQ4R LEARNING MODEL (PREVIEW, QUESTION, READ, REFLECT, RECITE AND REVIEW) WITH POP UP ON THE 2013 CURRICULUM THEMATIC LESSON CLASS V SD KECAMATAN BANYUDONO}

\begin{abstract}
This study aims to determine whether there is an effect of the PQ4R with Pop Up learning model on student learning creativity in the 2013 curriculum for the fifth grade thematic subjects and how much influence it has. From these objectives, this study uses a quasi-experimental method using a Pretest-Posttest Control-Group Design. In conducting the research, the research subjects were divided into two groups, namely the control group and the experimental group.

The control group was given a conventional learning model while the experimental group was given the PQ4R learning model with pop up, then data was taken on the creativity of learning thematic subjects from the two groups. The data on creativity in learning thematic subjects in both groups were analyzed using SPSS to answer the problem formulation. From the data analysis, it was obtained 0.000 or $<0.05$, which means that: Ho is rejected and accepts $\mathrm{H} 1$ or in other words there is a significant effect between the use of the PQ4R
\end{abstract}


Ninda, Luncana, Pengaruh Model Pembelajaran PQ4R

learning model with pop-ups on learning creativity in thematic subjects of class V students. From the regression test with SPSS obtained an $\mathrm{R}$ value of 0.786 , which means that there is a strong influence between the PQ4R learning model with pop up learning creativity in 2013 curriculum thematic subjects and the $\mathrm{R}$ square value is 0.625 which means that the PQ4R learning model with pop up has a positive effect on learning creativity. thematic subjects by $62.5 \%$

Keywords: PQ4R Model, Pop up, Creativity

\section{PENDAHULUAN}

Fungsi pendidikan sebagaimana tertuang dalam pasal 1 Undang-Undang nomor 20 tahun 2003 tentang Sistem Pendidikan Nasional, dikembangkan ke dalam tujuan pendidikan. Tujuan pendidikan sebagaimana tertuang dalam pasal yang sama adalah mengembangkan potensi peserta didik agar menjadi manusia yang beriman dan bertakwa kepada Tuhan Yang Maha Esa, berakhlak mulia, sehat, berilmu, cakap, kreatif dan mandiri. Mengelola tujuan pendidikan tidak lepas dari pelaksana pendidikan yaitu guru. Keberhasilan pendidikan sangat dipengaruhi oleh faktor pendidik.

Kemampuan mengajar harus dimiliki oleh pendidik/ guru yaitu kemampuan menyampaikan pelajaran kepada siswa dan juga guru harus bisa membuat siswa bersemangat, aktif serta tertarik dalam memahami apa yang disampaikan guru. Guru harus berusaha untuk meningkatkan kreatifitas dengan cara menggunakan model pembelajaran yang inovatif dan menarik, sehingga diharapkan dengan cara tersebut dapat mendukung keberhasilan belajar siswa dalam kegiatan belajar mengajar.

Berdasarkan kurikulum 2013 kegiatan pembelajaran yang baik adalah kegiatan pembelajaran yang mampu meningkatkan kreatifitas belajar siswa. Atas dasar tersebut guru harus mampu mengembangkan kegiatan pembelajaran yang sistematis berdasarkan model pembelajaran aktif. Salah satu model pembelajaran aktif yaitu dengan menerapkan model pembelajaran PQ4R with pop up. Model pembelajaran PQ4R menurut Trianto (dalam Handayani dan Sulisworo, 2016) merupakan bagian dari model-model pembelajaran inovatif berorientasi pada teori konstruktivisme. Teori pembelajaran konstruktivisme merupakan teori kognitif yang memiliki konsep siswa harus menemukan sendiri dan mentransformasikan informasi komplek, mengecek informasi baru dengan aturan-aturan lama dan merevisinya apabila aturan-aturan itu sudah tidak sesuai lagi. Menurut Trianto dalam (Wulandini, dkk: 2016) model pembelajaran PQ4R adalah suatu model pembelajaran yang digunakan untuk meningkatkan ingatan siswa dalam membaca dan menghafal pelajaran.

Media Pop-up menurut (Putri, dkk: 2018: 176) adalah sebuah gambar 3 dimensi yang 
Ninda, Luncana, Pengaruh Model Pembelajaran PQ4R

seolah-olah muncul keluar. Gambar di desain dengan warna-warna yang menarik, unik, dan memberi kesan tersendiri sehingga siswa akan lebih bersemangat mengikuti proses pembelajaran. Menurut Bluemel dan Talor (dalam Sugiarti, 2017: 69) Pop up adalah sebuah buku yang menampilkan potensi untuk bergerak dan interaksinya melalui penggunaan kertas sebagai bahan lipatan, gulungan, bentuk, roda atau putarannya. Menurut Dzuanda (dalam Sugiarti, 2017: 69) pop up adalah media pembelajaran yang memiliki unsur 3 dimensi serta memberikan visualisasi cerita yang dapat bergerak ketika halamannya dibuka. Рор ир sebagai media pembelajaran yang menarik dan variatif dapat membuat anak senang serta percaya diri dalam melakukan kegiatan belajar. Media рор up ini sangat penting untuk diterapkan khususnya di Sekolah Dasar karena taraf berfikir siswa masih pada tahap operasional konkret sehingga tujuan pendidikan yang diharapkan dapat tercapai sehingga dapat menumbuhkan kreatifitas belajar, keaktifan siswa serta kemandirian belajar siswa.

Menurut (Wulandari, 2019: 20) Kreatifitas belajar siswa adalah kemampuan yang dimiliki oleh setiap individu untuk dapat menciptakan dan menemukan sesuatu gagasan yang baru dengan cara pemikiran yang berbeda, ide dan model yang baru yang kemudian dikombinasi menjadi hal yang inovatif dan dapat dimengerti. Menurut Anderson (dalam Kau, 2017: 160) kreativitas belajar adalah proses yang dilalui individu ditengah-tengah pengalamannya dan menyebabkan individu tersebut untuk memperbaiki dan mengembangkan dirinya. Kreatifitas belajar mempunyai peranan penting dalam menentukan keberhasilan siswa dalam mempelajari kurikulum 2013. Siswa yang memiliki kreatifitas belajar tinggi akan merasa senang dan bersungguh- sungguh meskipun pelajaran tematik kurikulum 2013 itu sulit. Dengan adanya kreatifitas belajar tematik pada kurikulum 2013, siswa akan cenderung untuk memberikan perhatian dan pemahaman yang lebih, sehingga pembelajaran untuk mata pelajaran tematik merupakan salah satu pendekatan pembelajaran yang diterapkan pada kurikulum 2013. Menurut Akbar (dalam Anshory, 2018: 38) pembelajaran tematik merupakan suatu sistem pembelajaran yang memungkinkan siswa (baik individu maupun kelompok) aktif mencari, menggali dan menemukan konsep/ prinsip keilmuan secara holistik, bermakna dan otentik melalui tema tertentu. Dalam pelaksanaan pembelajaran tematik pendekatannya melibatkan beberapa bidang studi yang pemisahan mata pelajaran tidak begitu jelas untuk memberikan pengalaman kepada siswa.

Keunggulan model PQ4R ini adalah dapat menumbuhkan dan mengembangkan kreatifitas siswa dalam proses belajar mengajar yang dalam hal ini materi bacaan. Dengan diterapkan model pembelajaran ini siswa dapat menyimpan materi tersebut dari memori 
Ninda, Luncana, Pengaruh Model Pembelajaran PQ4R

jangka dan dapat membuat siswa disiplin dalam membaca. Model pembelajaran ini akan lebih maksimal apabila dikombinasi dengan media pembelajaran yang menumbuhkan keaktifan dan kreatifitas belajar siswa dalam mata pelajaran tematik kurikulum 2013 yaitu model PQ4R dikombinasi dengan media pop up. Sehingga model ini sangat cocok sekali diterapkan di SD pada kurikulum 2013 mata pelajaran tematik.

Berdasarkan pengamatan dan wawancara dari guru SD Kecamatan Banyudono diperoleh informasi bahwa dalam proses pembelajaran masih ada beberapa kendala yaitu : 1) Siswa kurang mau membaca 2) Dalam proses KBM siswa pasif 3) Guru masih mendominasi pembelajaran 4) Guru tidak menggunakan media pembelajaran dalam KBM 5) Kreativitas belajar siswa kurang. Berdasarkan nilai ulangan harian yang didapat dari guru SD Kecamatan Banyudono banyak siswa yang belum mencapai Kriteria Ketuntasan Minimal (KKM). Siswa masih memiliki nilai rata-rata dibawah KKM yaitu dibawah 70. Kendala yang dialami siswa yaitu dalam memahami materi.

Alternatif solusi yaitu dengan merancang pembelajaran yang menarik dan menyenangkan sehingga dapat meningkatkan keterlibatan siswa dalam proses pembelajaran dan dapat meningkatkan kreatifitas belajar serta kemauan siswa dalam membaca. Solusinya yaitu dengan model pembelajaran PQ4R (Preview, Question, Read, Reflect, Recite dan Review) with pop up. Tujuan penelitian pada artikel ini yaitu 1) Mengetahui pengaruh model pembelajaran PQ4R with pop up terhadap kreatifitas belajar pada kurikulum 2013 mata pelajaran tematik di SD Kecamatan Banyudono menjadi bermakna, 2) Mengetahui seberapa besar pengaruh model pembelajaran PQ4R with pop up terhadap kreatifitas belajar pada kurikulum 2013 mata pelajaran tematik di SD Kecamatan Banyudono.

\section{METODE}

Penelitian yang digunakan dalam penelitian ini adalah penelitian eksperimen semu (quasi-experimental research) dimana desainnya yaitu Pretest-Posttest Control- Group Design. Langkah-langkah desain pretest -posttest control group design adalah sebagai berikut:

"The following steps are involved in using a Pretest-Posttest Control-Group Design: (1) random assignment of research participants to experimental and control groups, (2) administration of a pretest to both groups (3) administration of the treatment to the experimental group but not to the control group, and (4) administration of a posttest to both groups”. (BorgdanGall, 2003: 392)

Dalam pelaksanaan penelitian subyek penelitian dibagi menjadi dua kelompok yaitu kelompok kontrol dan kelompok eksperimen. Kelompok kontrol diberikan model 
Ninda, Luncana, Pengaruh Model Pembelajaran PQ4R

pembelajaran konvensional sedangkan kelompok eksperimen diberikan model PQ4R with рор ир, kemudian diambil data kreatifitas belajar mata pelajaran tematik dari kedua kelompok kemudian dianalisis menggunakan SPSS untuk menjawab rumusan masalah.

\section{HASIL}

Tabel 1. Kenaikan nilai rata-rata kreatifitas belajar mata pelajaran tematik sebelum dan setelah perlakuan pada kelas kontrol

\begin{tabular}{|c|c|c|c|c|c|}
\hline \multirow[b]{2}{*}{ No } & \multirow[b]{2}{*}{ Deskripsi } & \multicolumn{2}{|c|}{ Nilai } & \multirow[b]{2}{*}{ Selisih } & \multirow[b]{2}{*}{ keterangan } \\
\hline & & Pre-test & Post-test & & \\
\hline 1 & Mean & 67,3 & 71,6 & 4,3 & Meningkat \\
\hline 2 & Median & 67 & 72 & 5 & Meningkat \\
\hline 3 & Modus & 64 & 70 & 6 & Meningkat \\
\hline 4 & Minimum & 60 & 60 & 0 & Sama \\
\hline 5 & Maksimum & 76 & 81 & 5 & Meningkat \\
\hline
\end{tabular}

Tabel 2. Kenaikan nilai rata-rata kreatifitas belajar mata pelajaran tematik sebelum dan setelah perlakuan pada kelas eksperimen

\begin{tabular}{|c|c|c|c|c|c|}
\hline \multirow{2}{*}{ No } & Deskripsi & \multicolumn{2}{|c|}{ Nilai } & \multirow{2}{*}{ Solisih } & Keterangan \\
\cline { 3 - 4 } & Mean & 64,6 & 85,4 & 20,8 & Meningkat \\
\hline 1 & Median & 63,5 & 83 & 19,5 & Meningkat \\
\hline 2 & Modus & 63 & 77 & 14 & Meningkat \\
\hline 3 & Minimum & 58 & 73 & 15 & Meningkat \\
\hline 4 & Maksimum & 71 & 107 & 36 & Meningkat \\
\hline 5 & &
\end{tabular}

Tabel 3. Perbandingan nilai rata-rata kreatifitas belajar pelajaran tematik

\begin{tabular}{|c|c|c|c|c|}
\hline \multirow{2}{*}{ No } & Deskripsi & Nilai & Nilai & \multirow{2}{*}{ Keterangan } \\
\cline { 3 - 4 } & & Kontrol & Eksperimen & \\
\hline 1 & Mean & 71,6 & 85,4 & Kontrol < Eksperimen \\
\hline 2 & Median & 72 & 83 & Kontrol < Eksperimen \\
\hline 3 & Modus & 70 & 77 & Kontrol < Eksperimen \\
\hline 4 & Minimum & 60 & 73 & Kontrol < Eksperimen \\
\hline 5 & Maksimum & 81 & 107 & Kontrol < Eksperimen \\
\hline
\end{tabular}


Ninda, Luncana, Pengaruh Model Pembelajaran PQ4R

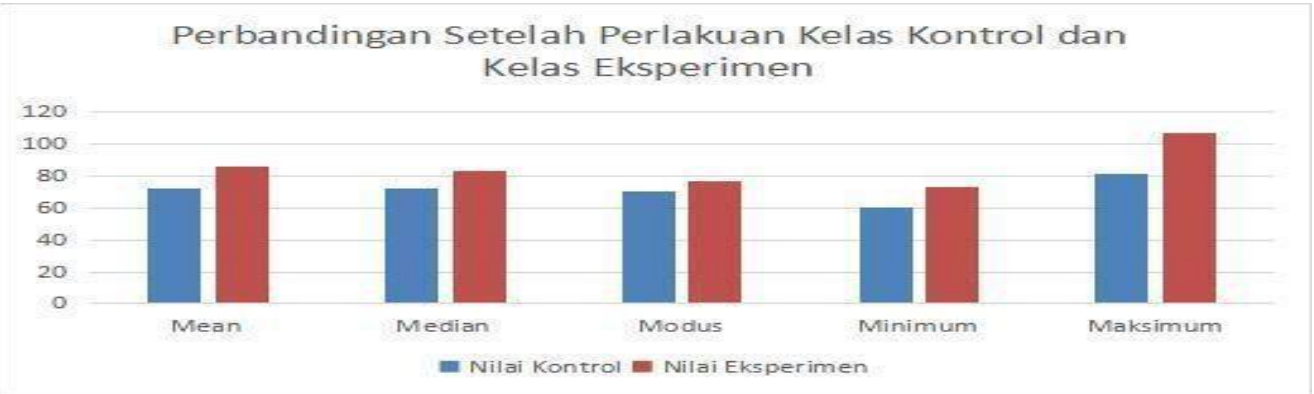

Gambar 1. Perbandingan nilai rata-rata kreatifitas belajar mata pelajaran tematik setelah perlakuan pada kelas eksperimen dan kelas control

Tabel 4. Uji hipotesis dengan Uji t Paired Samples Test

\begin{tabular}{|c|c|c|c|c|c|}
\hline \multirow{2}{*}{} & \multicolumn{2}{|c|}{ Paired Differences } & \multicolumn{2}{|l|}{} \\
\cline { 2 - 6 } & $\begin{array}{c}\text { 95\% Confidence Interval of } \\
\text { the Difference }\end{array}$ & \multicolumn{2}{|l|}{} \\
\cline { 2 - 6 } & Lower & Upper & $t$ & $\begin{array}{c}\text { Sig. (2- } \\
\text { tailed) }\end{array}$ \\
\hline
\end{tabular}

Tabel 5. Uji Regresi

Model Summary

\begin{tabular}{|c|r|r|r|c|}
\hline Model & $\mathrm{R}$ & $\mathrm{R}$ Square & \multicolumn{1}{|c|}{$\begin{array}{c}\text { Adjusted } \mathrm{R} \\
\text { Square }\end{array}$} & $\begin{array}{c}\text { Std. Error of the } \\
\text { Estimate }\end{array}$ \\
\hline 1 & $.786^{\mathrm{a}}$ & .625 & .460 & 7.48424 \\
\hline
\end{tabular}

a. Predictors: (Constant), model

Tabel 6. Sebaran kreatifitas belajar pelajaran tematik kelas eksperimen

\begin{tabular}{|c|c|c|c|}
\hline Rumus & Skor & Klasifikasi & $\begin{array}{c}\text { Jumlah } \\
\text { siswa }\end{array}$ \\
\hline $\mathrm{X}>\mathrm{Mi}+1,5 \mathrm{SDi}$ & $>112,5$ & Sangat tinggi & \\
\hline $\mathrm{Mi}+0,5 \mathrm{SDi}<\mathrm{X} \leq \mathrm{Mi}+1,5 \mathrm{SDi}$ & $87,6-112,5$ & Tinggi & 9 \\
\hline $\mathrm{Mi}-0,5 \mathrm{SDi}<\mathrm{X} \leq \mathrm{Mi}+0,5 \mathrm{SDi}$ & $62,6-87,5$ & Cukup & 17 \\
\hline $\mathrm{Mi}-1,5 \mathrm{SDi}<\mathrm{X} \leq \mathrm{Mi}-0.5 \mathrm{SDi}$ & $37,5-62,5$ & Kurang & \\
\hline $\mathrm{X} \leq \mathrm{Mi}-1,5 \mathrm{SDi}$ & $<37,5$ & Sangat Kurang & \\
\hline
\end{tabular}

\section{PEMBAHASAN}

Berdasarkan data untuk post test kreatifitas belajar mata pelajaran tematik pada kelas eksperimen dan kontrol, kelas eksperimen menunjukkan skor yang lebih baik daripada skor 
Ninda, Luncana, Pengaruh Model Pembelajaran PQ4R

kelas kontrol. Dari gambaran tersebut dapat dikatakan bahwa pembelajaran pada kelas kontrol maupun kelas eksperimen mengalami peningkatan, akan tetapi kelas eksperimen yang menggunakan model pembelajaran PQ4R with pop up lebih efektif dibandingkan dengan pembelajaran pada kelas kontrol. Hal ini dibuktikan secara signifikan melalui uji hipotesis terdapat perbedaan efektifitas dalam meningkatkan kreatifitas belajar mata pelajaran tematik siswa kelas V.

Beberapa faktor yang menyebabkan kelas eksperimen memiliki skor yang lebih baik dibanding dengan kelas kontrol diantaranya adalah:

1. Penggunaan model pembelajaran PQ4R with pop up mampu merangsang kreatifitas belajar mata pelajaran tematik siswa dibandingkan model pembelajaran konvensional.

2. Penggunaan model pembelajaran PQ4R with pop up mampu memberikan gambaran yang jelas tentang informasi yang akan disampaikan oleh guru sehingga siswa merasa senang dan lebih tertarik untuk menyelesaikan proses pembelajaran. Menurut Thomasalah dan Robinson (dalam Wangka dan Usman, 2017:68) langkah-langkah yang dilakukan dalam model pembelajaran PQ4R adalah:

a. Preview, dimaksudkan agar siswa membaca selintas dengan cepat mengajukan pertanyaan-pertanyaan pada diri sendiri untuk setiap pasal yang ada pada siswa

b. Read, baca buku dan bahan bacaan lainnya dengan efektif, yakni dengan cara pikiran siswa harus memberi reaksi terhadap apa yang dibacanya

c. Reflection adalah proses pengendapan pengalaman yang telah dipelajari, yang dilakukan dengan cara mengurutkan kembali kejadian-kejadian atau peristiwa pembelajaran yang telah dilaluinya

d. Recite, siswa diminta untuk merenungkan (mengingat) kembali informasi yang telah dipelajari dengan menyatakan butir-butir yang penting dengan nyaring dan dengan menanyakan serta menjawab pertanyaan-pertanyaan

e. Review, siswa diminta untuk membaca catatan singkat (intisari) yang telah dibuatnya kemudian siswa diarahkan agar mengulang kembali seluruh isi bacaan bila perlu dan sekali lagi menjawab pertanyaan yang telah dibuatnya.

Menurut Bluemel dan Taylor dalam (Dewanti, kegunaan media pop up adalah: 1) Untuk mengembangkan kecintaan anak terhadap buku dan membaca, 2) Dapat berguna untuk berfikir kritis dan mengembangkan kreatifitas 3) Dapat menangkap makna melalui perwakilan gambar yang menarik dan untuk memunculkan keinginan serta dorongan 
Ninda, Luncana, Pengaruh Model Pembelajaran PQ4R membaca.

Munandar dalam Istiqomah, Rochmad, Mulyono (2017) mengemukakan bahwa berpikir kreatif dapat dirumuskan sebagai kemampuan yang mencerminkan aspek-aspek kelancaran (fluency), keluwesan (flexibility), dan orisinalitas dalam berpikir (originality), serta kemampuan untuk mengembangkan, memperkaya atau memperinci suatu gagasan (elaboration). Kreativitas perlu dipupuk sejak dini dalam diri peserta didik dengan beberapa alasan yaitu: (1) Melalui berkreasi orang dapat mewujudkan (mengaktualisasi) dirinya, dan perwujudan/aktualisasi diri merupakan kebutuhan pokok pada tingkat tertinggi dalam hidup manusia; (2) Kreativitas atau berpikir kreatif merupakan kemampuan untuk melihat bermacam-macam kemungkinan penyelesaian suatu masalah; (3) Bersibuk diri secara kreatif tidak hanya bermanfaat (bagi diri pribadi dan bagi lingkungan) tetapi juga memberikan kepuasan kepada individu; dan (4) Kreativitaslah yang memungkinkan manusia untuk meningkatkan kualitas hidupnya. Semua orang dapat diasumsikan memiliki kreativitas, namun derajat dari kreativitas tersebut berbeda-beda (Solso dalam Siswono, 2011). Hal tersebut menunjukkan bahwa setiap orang memiliki tingkat kreativitas yang berbeda.

Berdasarkan uji hipotesis menggunakan uji t yang dimuat dalam tabel di atas menunjukkan bahwa nilai signifikansi sebesar 0,000 atau $<0,05$ yang berarti bahwa ada perbedaan kreatifitas belajar yang signifikan antara pre test dengan post test. Perbedaan tersebut disebabkan karena adanya perlakuan pada kelas eksperimen yaitu dengan menggunakan model pembelajaran PQ4R with pop up. Dari hasil analisis tersebut dapat disimpulkan bahwa Ho di tolak dan menerima $\mathrm{H}_{1}$ atau dengan kata lain pembelajaran tematik pada kurikulum 2013 menggunakan model pembelajaran PQ4R with pop up mempengaruhi kreatifitas belajar pada siswa kelas V SD.

Dari uji regresi dengan SPSS didapatkan nilai R sebesar 0,786 yang berarti bahwa ada pengaruh yang kuat antara model pembelajaran PQ4R with pop up dengan kreatifitas belajar mata pelajaran tematik adapun nilai $\mathrm{R}$ square sebesar 0,625 yang berarti bahwa model pembelajaran PQ4R with pop up berpengaruh positif terhadap kreatifitas belajar siswa pada mata pelajaran tematik kurikulum 2013 dengan total pengaruh sebesar 62,5\%.

Berdasarkan data post-test menunjukkan bahwa pembelajaran pada kelompok eksperimen yang menggunakan model pembelajaran PQ4R with pop up dapat dilihat kriteria kreatifitas belajar mata pelajaran tematiknya yaitu sebanyak 9 siswa atau sebesar 34,62\% memiliki kreatifitas belajar dalam kategori tinggi, dan 65,38\% memiliki kreatifitas belajar yang cukup atau dapat dikatakan bahwa pembelajaran dengan model pembelajaran PQ4R 
Ninda, Luncana, Pengaruh Model Pembelajaran PQ4R

with pop up efektif dalam meningkatkan kreatifitas belajar siswa.

Dalam model pembelajaran PQ4R penelitian ini relevan dengan hasil penelitian yang telah dilakukan oleh Marnita (2018), AlQawabeh dan Aljazi (2018), Indrawati, Riyadi, dan Matsuri (2014), Wahono (2014) yang menyimpulkan bahwa model PQ4R efektif meningkatkan pemahaman siswa dalam membaca. Selain itu, relevan juga dengan hasil penelitian yang dilakukan oleh Pratiwi, Yusrizal, dan Elisa (2016) dan Wondal (2016) yang menyimpulkan bahwa model PQ4R mampu meningkatkan hasil belajar siswa. Hasil-hasil penelitian tersebut menunjukkan model PQ4R mampu meningkatkan pemahaman konsep siswa melalui aktivitas membaca bahan ajar yang disediakan oleh guru. Melalui aktivitas membaca ini, siswa mampu mengonstruksi pemahamannya sehingga meningkatkan pemahaman konsep terhadap materi yang dipelajarinya.

Dalam media pop up penelitian ini relevan dengan hasil penelitian Dianita dan Subagyo (2017) yaitu media pop up sudah dikatakan sesuai dengan indikator hasil belajar siswa. Dari pembelajaran yang disajikan guru, sudah menunjukkan keingintahuan pada pembelajaran IPA, siswa sudah menunjukkan motivasi dalam belajar. Dengan menunjukkan keseriusan dalam belajar, sehingga dalam pengerjaan LKPD dan evaluasi semakin tinggi nilainya. Penelitian ini juga relevan dengan penelitian dari putri, yasbiati dan pranata (2018) dengan adanya pembelajaran media pop-up card, memudahkan dalam memahami materi, merasa lebih baik menggunakan media pop-up card dibandingkan dengan pembelajaran tanpa menggunakan pop-up card, dan merasa bisa menjawab pertanyaan dengan mudah setelah belajar dengan menggunakan media pop-up card. Media pop-up card lebih bisa mengaktifkan siswa untuk bisa ikut terlibat secara aktif sehingga konsentrasi siswa bisa lebih terarahkan dan siswa bisa lebih mudah dalam memahami materi, dari aspek kognitif dan aspek psikomotor siswa yang menggunakan media pop-up card lebih baik daripada kelas yang tidak menggunakan media pop-up card.

\section{KESIMPULAN}

Berdasarkan hasil analisis data dan pembahasan, maka dapat disimpulkan beberapa hal sebagai berikut:Berdasarkan uji hipotesis menggunakan uji t menunjukkan

nilai signifikansi sebesar 0,000 atau $<0,05$ yang berarti bahwa:Ho di tolak dan menerima $\mathrm{H}_{1}$ atau dengan kata lain ada pengaruh yang signifikan antara penggunaan model pembelajaran PQ4R with pop up terhadap kreatifitas belajar mata pelajaran tematik siswa 
Ninda, Luncana, Pengaruh Model Pembelajaran PQ4R

kelas V. Dari uji regresi dengan SPSS didapatkan nilai R sebesar 0,786 yang berarti bahwa ada pengaruh yang kuat antara model pembelajaran PQ4R with pop up dengan kreatifitas belajar mata pelajaran tematik dan dari nilai $\mathrm{R}$ square didapat nilai 0,625 yang berarti bahwa model pembelajaran PQ4R with pop up berpengaruh positif terhadap kreatifitas belajar sebesar $62,5 \%$

\section{UCAPAN TERIMA KASIH}

Peneliti mengucapkan terima kasih kepada Direktorat Riset dan Pengabdian Masyarakat, Direktorat Jenderal Penguatan Riset dan Pengembangan, Kementerian Riset, Teknologi dan Pendidikan Tinggi sebagai penyandang dana, terima kasih juga kepada SD Negeri Kecamatan Banyudono atas kerjasamanya dalam proses penelitian dan berbagai pihak yang telah membantu penelitian sampai selesai.

\section{DAFTAR PUSTAKA}

Al-Qawabeh, R. H. \& Aljazi, A. A. 2018. The Effectiveness of Using PQ4R Strategy in Teaching Reading Comperehension in Arabic Language Subject among Ninth Grade Students' Achievement in Jordan. World Journal of Educational Research. 5(2), 159 $-171$

Anshory, dkk. 2018. Pembelajaran Tematik Integratif Pada Kurikulum 2013 di Kelas Rendah SD Muhamadiyah 07 Wajak. Jurnal Inovasi Pembelajaran, 4(1), 35-46.

Borg, W. R. \& Gall, M. D. 2003. Educational research: an introduction (7thed). New York. Longman, In

Dewanti, Toenliou dan Soepriyanto. 2018. Pengembangan Media Pop Up Book Untuk Pembelajaran Lingkungan Tempat Tinggalku Kelas IV SDN 1 Pakunden Kabupaten Ponorogo. Jurnal Kajian Teknologi Pendidikan, 1(3), 221-228

Dianita, Shabrina dan Subagyo. 2017. Penggunaan Media Pop Up Untuk Meningkatkan Hasil Belajar Tema Ekosistem Kelas V. Jurnal Penelitian Guru Sekolah Dasar, 5 (3), 883-892

Handayani dan Sulisworo. 2016. Penerapan Model Pembelajaran PQ4R Pada Kurikulum 2013 Untuk Meningkatkan Keaktifan Belajar dan Hasil Belajar Siswa. Proseding Seminar Nasional Sains dan Pendidikan Sains 5. Yogyakarta: Universitas Ahmad Dahlan

Indrawati, T., Riyadi, \& Matsuri. 2014. Pengaruh Metode Pembelajaran Preview, Question, 
Ninda, Luncana, Pengaruh Model Pembelajaran PQ4R

Read, Reflect, Recite, and Review (PQ4R) Terhadap Kemampuan Membaca Pemahaman.Jurnal Didaktika Dwija Indria. 2(9)

Istiqomah,F., Rochmad, \& Mulyono. 2017. Mathematical Creative Thinking Ability of the Seventh Grade Students in Terms of Learning Styles to the Preview- Question-ReadReflect-Recite-Review (PQ4R) Learning. Unnes Journal of Mathematics Education, 6(2), 258-267

Kau, Murhima. 2017. Peran Guru Dalam Mengembangkan Kreativitas Anak Sekolah Dasar.

Proceeding Seminar Dan Lokakarya Nasional Revitalisasi Laboratorium dan Jurnal Ilmiah Dalam Implementasi Kurikum Berbasis Bimbingan dan Konseling Berbasis KKNI, 4-6 Agustus 2017. Malang: Universitas Negeri Malang

Marnita. 2018. The Effect of Using PQ4R (Preview, Question, Read, Reflect, Recite, Review) Strategy on EFL Students' Reading Comprehension Achievement. Research in English and Education Journal, 3(1), 17 - 24

Putri,Ghina Fitriadi, Yasbiati dan Pranata. 2018. Pengaruh Media Pop-Up Card terhadap Hasil Belajar Siswa pada Materi Penggolongan Hewan berdasarkan Jenis Makanannya. Pedadidaktika: Jurnal Ilmiah Pendidikan Guru Sekolah Dasar, 5(1), 174-183

Pratiwi, A. D., Yusrizal, Y., \& Elisa, E. 2016. Pengaruh Penggunaan Strategi Pembelajaran PQ4R (Preview, Question, Read, Reflect, Recite, Review) terhadap Hasil Belajar Siswa pada Materi Gerak Kelas VII SMP Negeri 1 Baitussalam. Jurnal Ilmiah Mahasiswa Pendidikan Fisika Unsiyah, 13(2), 131- 141.

Putri, dkk. 2018. Pengaruh Media Pop Up Card Terhadap Hasil Belajar Siswa Pada Materi Penggolongan Hewan Berdasarkan Jenis Makanannya. Pedadidaktita: Jurnal Ilmiah Pendidikan Guru Sekolah Dasar. 5(1), 174 -183

Siswono, T.Y.E. 2011. Level of Student's Creative Thinking in Classroom Mathematics. Educational Research. Unnes Journal of Mathematics Education, 6(2), Agustus 2017 Review. 6(7): 548-553

Sugiarti, Henry. 2017. Keefektifan Media Pop Up Candi Berbantuan Model Snowball Terhadap Pembelajaran IPS Kelas V SDN Kembangarum 02 Mreanggen. Jurnal Pendas Mahakam, 2 (1), 67-71

Wahono, S. 2014. Using PQ4R to Increase The Students' Reading Comprehension at A1Bidayah Islamic Boarding School. Fenomena. 13(2), 121 - 131.

Wangka dan Usman. 2017. Penerapan Strategi Pembelajaran PQ4R Dalam Meningkatkan 
Ninda, Luncana, Pengaruh Model Pembelajaran PQ4R

Prestasi Belajar PA1. Jurnal Tarbawi, 1(1), 68

Wondal, R. 2016. Penggunaan Model Pembelajaran Preview, Questions, Read, Reflect, Recite, Review (PQ4R) untuk Meningkatkan Aktivitas dan Hasil Belajar Biologi. Jurnal Pendidikan Dasar UNJ, 7(1), 128 - 139.

Wulandini, dkk. 2016. Pengaruh Strategi Belajar PQ4R Terhadap Hasil Belajar Kognitif Sejarah Siswa. Jurnal Pendidikan dan Penelitian Sejarah, 3(6), 1-14

Wulandari, Koeswanti dan Giarti. 2019. Penerapan Model Project Based Learning Berbantuan Media Pop Up Book Untuk Meningkatkan Kemampuan Berfikir Kreatif Siswa Kelas V. Jurnal Pendidikan Dasar Indonesia, 4(1), 19-2 